\title{
What is the Purpose of Ethnobiology in Biology Teacher Training?
}

\author{
Geilsa Costa Santos Baptista* \\ Department of Education, State University of Feira de Santana, Brazil
}

*Corresponding Author: geilsabaptista@gmail.com

\section{ABSTRACT}

This article aims to discuss the purpose of ethnobiology in biology teachers' training based on conceptions of biology teachers before and after their participation in a training course for science teachers that involved ethnobiology. The research was developed in 2009 and involved semi-structured interviews with nine biology teachers of public schools in the state of Bahia (Northeastern Brazil). Analyzes were conducted inductively, using categories based on the teachers' answers and carefully studying literature on science teaching. Results indicate that teachers expanded their conceptions about ethnobiology after their participation in the training course. They perceived this science as the study of complex relationships between human beings and other living beings. They also perceived the importance of exploring their students' cultural knowledge to the intercultural dialog and having ethnobiology as a tool in this process. It is concluded that ethnobiology contributes to the biology teachers' training guiding his/her practices and giving the opportunity to identify students' cultural knowledge that can be used in an intercultural dialog with the biology taught in schools; hence, it is imperative to offer training courses for teachers as a starting point.

KEY WORDS: ethnobiological research; science teacher training; cultural diversity; intercultural dialog; cultural knowledge

\section{INTRODUCTION}

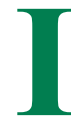

n science teaching, it is important for teachers to identify students' cultural knowledge. This kind of identification promotes opportunities for intercultural dialog between the scientific knowledge and the knowledge of the sociocultural backgrounds of the students that they take to the classrooms. In this dialogic relation, teachers need to be careful with the knowledge presented by the students so that they understand their meanings and how this knowledge may be related to the teaching contents. Dialog is a culturally appropriate, pedagogical practice; in a way, it can help students realize that science is not the only means to access knowledge. It encourages students to think and reflect critically about different knowledge and ways of knowing, and the similarities and differences between them (Baptista, 2007).

Relevant studies of ethnobiology have elucidated various types of knowledge that people have within their sociocultural contexts constructed from numerous relationships with nature around them (Diegues, 2004; Nascimento et al., 2009; and Duran et al., 2010). According to the International Society of Ethnobiology (ISE, 2012), ethnobiology is the study of the complex relationships that exist between living beings and cultural systems, both in the past and current societies. Ethnobiology studies the knowledge and concepts of living beings developed in certain communities that live in direct contact with nature (Righetti, 2004). In other words, ethnobiology studies traditional knowledge and practice that result from countless relations established between human societies, their cultures, and other living beings. Traditional knowledge - also cited as ethnobiological knowledge, traditional ecological knowledge, or local knowledge - is defined by Berkes and Folke (1998) as a cumulative body of knowledge, practices, and cultural beliefs about the relationship of living beings (including humans) with one another and with the environment.

To El-Hani (2001), ethnobiology is important to the comprehension of how people interact with the world around them, physically, symbolically, cognitively, and affectively. Ethnobiological research contributes to finding solutions to ecological problems in vast regions of the world - for example, the destruction of forests in tropical areas and the extinction of animal and vegetal species - revealing knowledge of people who coexist sustainably with nature around them. Bandeira (2001) adds that ethnobiological studies can contribute to the elaboration of environmental public policies that include not only biological but also cultural diversity, which is a fundamental element of these policies. Furthermore, preserving local knowledge constitutes heritage of humanity (Posey, 1997). These ethnobiological research characteristics are related to the societies' values and, therefore, have influence into the educational aspects of schools.

In science education, in addition to the aspects mentioned above in relation to teaching contents, ethnobiology fulfills the important role of assisting teachers by its methodological 
researching procedures, in research and understanding the cultural diversity and students' cultural knowledge (Baptista and El-Hani, 2009). As a result, teachers could elaborate and implement teaching strategies, which include and consider the knowledge belonging to the students' sociocultural means through dialog with the scientific knowledge. However, according to Baptista and El-Hani, to ensure a cultural dialog in science classrooms, awareness is needed among teachers about the presence of cultural diversity in these spaces. The term cultural diversity is here understood as the multiplicity of cultures that are present in classrooms. First by the students, who are coming from various social means. Second, teachers also coming from various social means. Moreover, the science is the scientists' cultural activity. A sensitive science teaching that embraces cultural diversity occurs when the diversity of students' traditional knowledge and cultural manifestations are investigated, understood, and considered to promote intercultural dialog in classrooms (Baptista and El-Hani, 2009).

The purpose of this paper is to present and discuss the purpose of ethnobiology into the training and pedagogical practice of biology teachers. It is explored through a study that sought to reveal the conceptions of biology teachers of ethnobiology and how this science can contribute to intercultural biology teaching, before and after their participation in a continuing training course for biology teachers involving ethnobiology.

The research questions for this study are:

1. How do science teachers conceive ethnobiology?

2. Does the inclusion of ethnobiology contribute to teaching practices that consider promote the concept of cultural diversity in classrooms?

From an earlier study, it was found possible to reflect on the importance of listening to teachers during their professional development process, especially the training process that involves their own pedagogical practice in schools and/or continuing training courses about the cultural diversity present in their classes.

The training course presented in this article assumed that the teacher who becomes an investigator of his or her own pedagogical practice ceases to be a task executor, or the mere transmitter of content, and becomes a researcher in the classroom (Nóvoa, 1992). Research undertaken by teachers contributes to their reflection, as well as building a personal way of knowing and stimulating progression in their pedagogical knowledge (Schön, 1992). To Schön (1992), reflection is deeply linked to action. Instead of trying to apply theories and scientific concepts in practical situations, professionals (such as teachers) need to learn to associate those theories and concepts to problems that are confronted in their scholarly realities, researching them in a reflexive way to try to modify actions and find solutions to these problems. In the specific case of science education and its interconnection with cultural diversity, this research involves inquiries made by teachers about students' cultural knowledge with the specific purpose of contributing to the pedagogical practice based on the dialog between that cultural knowledge and the scientific knowledge that is being taught (Baptista and El-Hani, 2009).

The teachers, just like any other human beings, are the actors of their own development, in all aspects, and, therefore, are reflexive and capable to make decisions to confront the problems in their pedagogical practices. Thus, teacher training courses must encourage reflections and expositions of their experiences on different topics involving didactic activities. This constitutes opportunities to hear the teachers, their conceptions, and wishes to improve the quality of science teaching and learning and the relations to other cultures, just as proposed in this study.

\section{METHODOLOGY}

\section{Theoretical Approach, Participants, and Research Context} The study was developed in 2009 in Feira de Santana city which is located in the semi-arid region of Bahia state, Northeast of Brazil.

The research methodology was qualitative, based on semistructured interviews (Martins, 2004). According to Bogdan and Biklen (2003), one of the basic characteristics of qualitative research is that, based on the collections of descriptive data, it tries to understand meanings given to contexts. In qualitative research, investigators are more interested in the process than in the results, and data analysis tends to be inductive (Bogdan and Biklen, 2003). There is no data collection or proof with the aim to confirm or deny hypotheses previously constructed; instead, abstractions are constructed when data are grouped. To Alasuutari (2010), data analysis in qualitative research tends to be conducted inductively using raw data, where detailed readings result in concepts, subjects, or models.

A semi-structured interview is a research technique in which the researcher starts from partially formulated questions and adds further questions according to the statements of respondents (Bogdan and Biklen, 2003).

During the registration period, 14 teachers filled in the application forms to participate, but only 9 teachers completed the training course. The teachers, who dropped out, two males and three females, claimed that they did not receive permission from their school principals to participate in the training course. To participate in this training course, the teacher should have an undergraduate degree in school science teaching: Chemistry, physics, or biology.

The nine participating teachers were all female, aged 28-41. They were teaching in schools in traditional communities, often farming communities, in towns of the regions of Salvador, Euclides da Cunha, Feira de Santana, and Serra Preta. Four participating teachers taught biology in a middle school and five teachers taught natural science and biology in both, middle school and high school.

All the participating teachers had undergraduate degrees in biology science teaching. They graduated from college 
between 1995 and 2007. They had also finished graduate courses in different areas such as botany, environmental education, public health, and civil engineering at Brazilian public or private universities.

To participate in the training course, the teachers signed a term of consent form, as required by the resolution 196/96 of the Brazilian Ministry of Health, which deals with ethical issues of research involving human beings (Brazil, 2003). The training course developed in 2009 at the State University of Feira de Santana (UEFS) was designed exclusively for science teachers of public schools in the state of Bahia. The purpose of this course was to increase awareness of these teachers about intercultural dialog in school science education, with the help of the ethnobiology.

The course, with a total workload of 132 academic hours, consisted of a theoretical and a practical approach, both interconnected. The theoretical development included the following topics: Ethnobiology, concepts, aim of the study, methodological procedures, and research contributions to science education, as well as the relevance of the research of teaching practice and students' cultural knowledge to the cultural dialog in science teaching. The objective of this approach was to generate spaces for discussion on the theoretical aspects that involve ethnobiology and science teaching. The practical approach involved the following: Analysis of texts related to the topic, research on ethnobiology to investigate students' traditional knowledge in schools where the participating teachers' work, production of teaching materials and teaching strategies containing students' traditional knowledge and relations of similarities and differences with the biological scientific knowledge, and interventions in biology teaching in schools where teachers' work is based on cultural dialog. These interventions were considered appropriate for teachers to evaluate the influence of the course on their teaching activities, if they would insert the intercultural dialog in their classrooms.

\section{Data Collection}

The interviews were conducted in classrooms of the SState University of Feira de Santana (UEFS), Bahia, Brazil, where the course was held with biology teachers involving an ethnobiology and their contributions to a science teaching that considered cultural diversity. Nine teachers of biology of public schools in the state of Bahia, Brazil participated in the interviews, with the following questions:

1. Do you seek to determine what cultural knowledge that students bring to the classroom?

2. If yes, which methodology do you adopt?

3. What is ethnobiology and what is its research methodology?

The participating teachers answered the same three questions before and after their training course. The training course was designed and instructed by the researcher of the study (author of this paper). The aim was to find out, through the conceptions identified by the teachers themselves, if the course contributed to their understanding of the significance of ethnobiology, its contributions to science education to raise awareness of cultural diversity, and its importance in enabling intercultural dialog in classrooms.

Each interviewed teacher (IT) received a code of identification to ensure their confidentiality. Those codes were used during data analysis and to report the results, for example, IT1, IT2, and so on. The responses were documented with a digital recorder and later transcribed to a text editor.

\section{Data Analysis}

Once the interviews were transcribed, two categories were created according to the questions and teachers' answers. A table was constructed for each category and the answers were divided into (a) teachers who have already had contact with ethnobiology and (b) teachers who have never had contact with ethnobiology. Both subcategories compare the answers before and after the participation in the training course.

Teachers who have had ethnobiology as a part of their academic curriculum or have participated in training courses on this subject were considered teachers who have already had contact with ethnobiology, as opposed to those teachers who have never studied ethnobiology. The objective was to compare answers, before and after the course, and to identify changes in each participant's conceptions. Data analysis was conducted inductively, based on teachers' conceptions and dialogs with specific literature of science teaching.

\section{RESULTS AND DISCUSSION}

The following categories were created from the participating teachers' answers:

\section{Category 1: Concept of Ethnobiology}

Answer sample about the concept of ethnobiology given by teachers shown in Table 1.

\section{Category 2: Importance of Investigating Students' Traditional Knowledge and its Relationship with Ethnobiology}

Answer sample about the importance of investigating students' traditional knowledge and its relationship with ethnobiology shown in Table 2.

\section{Category 1: Concept of Ethnobiology: Before and After the Training Course \\ Before the training course}

Answers given by teachers who have already had contact with ethnobiology converged to the following understandings: (1) ethnobiology as the study of cultural knowledge (Ex. IT1, Table 1), and (2) ethnobiology as the study of biological knowledge of certain social groups and their relations with science, with the aim to compare (Ex. IT4, Table 1).

The answers given by the teachers who have never had contact with ethnobiology showed that, for them, this was a study that reveals the human adaptation and their beliefs about nature (Ex. IT3, Table 1). Some teachers failed to provide a definition, 


\section{Table 1: Answer sample about the concept of ethnobiology given by teachers}

\section{Teachers who already have had contact with ethnobiology}

Before the course

the forms of culture... (IT1)

The study of biological relationships ... the human being in the social context, what one has the knowledge ... within the place one lives, comparing to the question of how science really is, as a scientific knowledge (IT4)

Teachers who have never had contact with ethnobiology

Before the course
between nature, people's adaptation, and their beliefs ... (IT3).

We hear about ethnobiology, but I never got to read the definition of what ethnobiology is. Ethnobiology ... ethno comes from what word? (IT6)

\section{After the course}

It is a type of knowledge, a science that aims to explain the relations between human beings and cultural traditions and what is done with nature. The relation of human beings and their culture with the nature... (IT1)

[Ethnobiology] is the study $<\ldots>$ of cultural relationships the culture of specific population, a specific community. Ethnobiology works with communities, with cultural issues, the very understanding of nature, from generations to generations. It studies the knowledge that is passed from parents to children (IT5)

\section{After the course}

It is a discipline, an area that combines biology and anthropology to study how traditional societies relate to the natural world around them. $\langle\ldots\rangle$ Ethnobiology is a discipline that studies these interactions of living beings and cultural systems. That was clear to me... $<\ldots>$ The interactions of cultures with the natural world (IT3)

Now, I can talk a little bit about ethnobiology in the sense that it studies social groups, $<\ldots>$ their relationship with nature, with the environment that surrounds them $\langle\ldots>$. Not only here or now, but it seeks to understand the past of that group $\langle\ldots>$ using a historical, social, and cultural approach $<\ldots>$ (IT6)

\section{IT: Interviewed teacher}

for example, IT6 (Table 1). When analyzing the concept of ethnobiology in literature, a unified concept does not exist. The consensus for most ethnobiologists is that this field of research aims to study, in the broadest sense possible, the complex set of relationships of plants and animals with past and present human societies (Berlin, 1992). Thus, it is possible to claim that teachers who had already had contact with ethnobiology gained more understanding of what this science is than those who had not approached it before.

Teachers who have already had contact with ethnobiology in some cases showed inadequacies in their responses, for example, IT4 in Table 1. For IT4, ethnobiology, after investigating popular knowledge, seeks a scientific explanation. In other words, IT4's answer suggests the conception that the goal of ethnobiology is the validation of traditional knowledge based on modern Western science. This conception is not adequate because ethnobiological studies primarily seek a dialog between the local/traditional knowledge and the academic scientific knowledge, to result in mutual contribution (Diegues and Arruda,2001; Pérez-Ramírez et al., 2004).

\section{After the training course}

The teachers' answers were unanimous identifying ethnobiology as the science that studies the interactions established between human beings as a cultural being and the nature around them. This explanation is consistent with the sense of conjunction of ethnobiology with science teaching in schools to investigate and understand the nature-related traditional knowledge of students (Baptista, 2007; Baptista and El-Hani, 2009). The reflections of IT3, IT5, and IT6 indicate teachers' understandings about the meaning of ethnobiology (Table 1).

\section{Category 2: Importance of Investigating Students'}

\section{Traditional Knowledge and its Relationship with} Ethnobiology: Before and After the Training Course

\section{Before the training course}

Teachers answered that it was important to investigate the traditional knowledge of their students because it allowed the teachers to understand students' conceptions, and to establish relationships between daily situations and teaching content. IT1 and IT4's answers can be analyzed as examples in Table 2. Certainly, ethnobiological research can enable the teacher to elucidate the cultural knowledge of students, especially their traditional knowledge, which is produced within traditional communities, and to which ethnobiology has dedicated most of its attention (Diegues and Arruda, 2001). With this knowledge, the teacher will lead the establishment of relationships with scientific knowledge, whether in terms of how similar or how different they are (Baptista and El-Hani, 2009), which may contribute to expanding students' knowledge with scientific knowledge (Cobern and Loving, 2001). Teachers can create opportunities for argumentations where students can understand the meanings they themselves assign to teaching content. To Acar (2015), arguments are statements of positions on a problem. Therefore, the argument in science classes allows a reasoning process between different positions, either from teachers and/or from students on a scientific topic.

The teachers who have never had contact with ethnobiology did not know how to answer the question about the importance of investigating students' traditional knowledge. This could be so because they were unable to give a clear definition of ethnobiology; some teachers gave answers that were incorrect and did not match specific literature and others could not provide an answer. 
Table 2: Answer sample about the importance of investigating students' traditional knowledge and its relationship with ethnobiology

Teachers who already have had contact with ethnobiology

\section{Before the course}

It is a way to get information about something and add it to the scientific knowledge that we have, even as a content of the discipline $<\ldots>$ specific to one school... (IT1)

Considering the cultural issues, I think, that depends on and varies from one region to another where they live, to incorporate their knowledge into scientific knowledge $<\ldots>$ taking into consideration their knowledge on the topic being taught (IT4)

Teachers who have never had contact with ethnobiology

\begin{tabular}{ll}
\hline Before the course & After the course \\
\hline There was no answer & $\begin{array}{l}\text { I think it's important }<\ldots>\text { to see the student's reality }<\ldots>\text {, their knowledge. It's } \\
\text { very interesting, because it makes lessons more interesting for them (IT6) } \\
<\ldots>\text { For sure, but I think it's not easy... Within the current teaching approach, } \\
\text { where we have a curricular component, classrooms are organized to meet the } \\
\text { workload demand, to take care of ethnobiology is an additional requirement [after] } \\
\text { control of students, discipline control... It doesn't mean that I don't want to } \\
\text { change that, but the school structure has its proper curriculum organization. } \\
\text { The teacher in a public school }<\ldots>\text { does not have a full autonomy to research } \\
\text { and investigate such knowledge. There are many obstacles, one of them is the } \\
\text { teacher's situation in terms of number of students, number of groups, and hours } \\
\text { of class time... You can see that it's difficult but not impossible and should even } \\
\text { be adopted and gradually inserted. It is necessary to understand that changes don't } \\
\text { happen in an hour. Planning is an activity that is included in teachers' schedules, } \\
\text { but a plan that considers traditional knowledge after investigating it, this requires } \\
\text { time... (IT8) }\end{array}$ \\
\hline
\end{tabular}

\section{After the course}

Sure, now I am already trying to appreciate the students' culture and tradition as much as possible, what they already bring with them to the classroom $<\ldots>$ within certain teaching content. It is important (IT1)

Yes, I have already worked with the perspective of their knowledge but for sure it was not the vision as open as I have now (because of ethnobiology). We know things from academia, but students ask some questions: "Teacher, do you know this, do you know that?" I don't... Then, I also need to research, to ask them what it is. Because, in dialog, I cannot work with a subject that I don't know in that moment $\langle\ldots>$. Students are going to school unmotivated because they don't understand why there are so many academic topics that don't have meaning in their everyday lives. For example, why I need to know the scientific name of mosquitoes $\langle\ldots>$ /If I know that a mosquito is the little insect that bites people and leaves a red point on the skin, would that not be enough? I think school must raise individuals $\langle\ldots\rangle$. Schools won't eliminate their traditional knowledge, but you, as a teacher, can increase their academic knowledge, expand their worldview (IT5)

\section{After the training course}

Right after the course, the answers were unanimous on the importance for science education to include investigation of students' traditional knowledge, as it contributes to changes in pedagogical practice to make classrooms more interesting in terms of the content of teaching, as expressed, for example, in IT1 and IT6's reflections (Table 2). Regarding IT1's answer, it is interesting to note how she emphasizes the term "teaching content," without considering the arguments given by students with respect to that content. To Osborne et al. (2001), it is not enough for students to talk about scientific content presented in classrooms, it is necessary to discuss the reasons that support their ideas. In this sense, the teacher must create opportunities through questioning (Osborne et al., 2001). These questions will generate opportunities to establish a dialog where students will present their arguments - their cultural knowledge that comes from their surroundings and that might or might not be based in science - and, in the same way, teachers would give scientific explanations. For Sasseron and Carvalho (2014), argumentation contributes to science learning because it is a strategy for reasoning where data, evidence, beliefs, and knowledge are mobilized to the construction of scientific knowledge. In addition, the involvement of questions in science classes may be a kind of experimental work done by scientists, which would require the students to increase their capacity for reflection and critical thinking (Zion and Mendelovici, 2012).

All the participant teachers perceived the investigation of students' cultural knowledge as important to improve their teaching practice having the ethnobiology as a tool for this. Although they also revealed their wishes to see changes in their pedagogical practices in this respect, and one of them, IT8 (Table 2), pointed out some obstacles. She argued that the curriculum structure, time, number of students per class, teacher's responsibilities in school, and the lack of autonomy all obstruct changes in pedagogical practices, including research on and consideration of students' cultural knowledge. IT8 raided interesting arguments about issues that are common in the social environment of teachers within schools, particularly public schools, which were the focus of this research. There is no doubt that the working conditions of teachers interfere with expansion of their knowledge and pedagogical practices (Tardif, 2002), often inhibiting changes, such as including research and consideration of students' traditional knowledge into those practices. 
According to Fagundes (2016), it is important to recognize the problems that have an impact on pedagogical practices as well as engage in critical reflections on the working conditions, to generate, within limits, actions that can improve them. In this sense, IT8 also seemed to offer some solutions to the problems she herself had identified, thinking optimistically about the possibility of changes in her pedagogical practice regarding the investigation of students' cultural knowledge, so the ideas learned during this course given by the researcher may result in actions. This was clear when she argued that changes in their pedagogical practice regarding the investigation and consideration of cultural knowledge of students are not impossible and could be adapted gradually, with time and while gaining more teaching experience.

\section{CONCLUSIONS}

Teachers' answers after their participation in the training course involving ethnobiology revealed that they expanded their conceptions identifying this science as the study of complex relationships established between human beings and other living beings. From this conception, teachers recognized the importance of investigating students' traditional knowledge. Ethnobiology was also identified as a tool to support this process of investigation because it allows the teachers to establishm relationships between scientific biological knowledge taught in classrooms and the cultural knowledge from social environments of the students.

It can be claimed that ethnobiology contributes to science teaching and consequently to the science teacher training, providing the teachers with the opportunity of epistemological reflections involving the different knowledge systems that are present in classrooms, including the science being taught and the students' cultural knowledge.

It becomes important to provide continuing training courses involving ethnobiology for science teachers who are already exercising their activities in schools because this may contribute to changes in their teaching practices, and to increased respect and consideration for the diversity of cultural knowledge during their teaching activities. These teachers would unlikely have time to reflect, individually and collectively, with their peers, on the problems, successes, and prospects of the teaching practice. Courses involving ethnobiology create conditions for biology teachers to understand its concepts and methodological procedures and, thus, to reflect on their importance to teaching science practice in a way that is sensitive to cultural diversity, considering the students' cultural knowledge.

However, it is always necessary to understand the realities and aspirations of these teachers, as this may open space for new ideas and solutions to the problems teachers face in their activities, for example, working conditions identified by the teachers who participated in this study, such as obstacles to combine research and teaching practice. As stated by Brownlee et al. (2003), to know teachers' views on teaching may mean assistance for effective learning to the preparation of these professionals into the teachers training programs.

\section{ACKNOWLEDGMENTS}

I would like to thank the collaboration of teachers who participated in the training course and the support of the Department of Education of the State UEFS.

\section{REFERENCES}

Acar, O. (2015). Examination of science learning equity through argumentation and traditional instruction noting diferences in socioeconomic status. Science Education International, 26(1), 24-41.

Alasuutari, P. (2010). The rise and relevance of qualitative research. International Journal of Social Research Methodology, 13(2), 139-155.

Baptista, G.C.S. (2007). A Contribuição da Etnobiologia Para o Ensino e a Aprendizagem de Ciências: Estudo de Caso em Uma Escola Pública do Estado da Bahia [Ethnobiology's contribution to science teaching and learning: A case study in a public school in the Bahia state]. Master's thesis in Teaching, philosophy and history of science. Salvador: Federal University of Bahia-State University of Feira de Santana.

Baptista, G.C., \& El-Hani, C.N. (2009). The contribution of ethnobiology to the construction of a dialogue between ways of knowing: A case study in a Brazilian public high school. Science and Education, 18(3-4), 503-520.

Berkes, F., \& Folke, C. (1998). Linking Social and Ecological Systems: Management Practices and Social Mechanisms for Building Resilience. New York: Cambridge University Press.

Bandeira, F.S.F. (2001). Construindo uma epistemologia do conhecimento tradicional: Problemas e perspectivas [Constructing an epistemology of traditional knowledge: Problems and perspectives]. Proceedings of I Baian Meeting of Etnobiology and Etnoecology. Feira de Santana: State University of Feira de Santana. pp. 109-133.

Berlin, B. (1992). Ethnobiological Classification: Principles of Categorization Plants And Animals in Traditional Societes. Princeton, NJ: Princeton University Press.

Bogdan, R.C., \& Biklen, S.K. (2003). Qualitative Research for Education: An Introduction to Theory and Methods. $4^{\text {th }}$ ed. Boston, MA: Allyn and Bacon.

Brazil-Ministry of Health (2003). Normas para Pesquisa Envolvendo Seres Humanos. $2^{\text {nd }}$ ed. [Norms for research involving human subjects]. Brasília, Brazil: National Health Council \& National Research Ethics Commission.

Brownlee, J., Purdie, N., \& Boulton-Lewis, G. (2003). An Investigation of student teachers' knowledge about their own learning. Higher Education, 45, 109-125.

Cobern, W.W., \& Loving, C.C. (2001). Defining science in a multicultural world: Implications for science education. Science Education, 85, 50-67.

Diegues, A.C., \& Arruda, R.S.V. (2001). Saberes Tradicionais e Biodiversidade no Brasil [Traditional knowledge and biodiversity in Brazil]. Brasília, Brazil: Ministry of the Environment.

Diegues, A.C.S. (2004). A mudança como modelo cultural: O caso da cultura caiçara e a urbanização [Change as a cultural model: The case o caiçara's culture and urbanization]. Enciclopédia Caiçara. Vol. 1. São Paulo, Brazil: Hucitec.

Duran, E.N., Cordero, W.J.A., \& Betancourt, S.F.H. (2010). Conocimento tradicional sobre el uso y aprovechamiento de la fauna silvestre en la reserva municipal de Cuxtal, Yucatán, México [Traditional knowledge about the use and development of wildlife in reserve of Cuxtal town, Yucatan, Mexico]. In: Fuentes, A.M., Silva, M.T.P., Méndez, R.M., Azúa, R.V., Correa, P.M., \& Santillán, T.V.G., (Eds.), Sistemas Biocognitivos en la Conservación Biológica y el Fortalecimiento Cultural. México: Asociación Méxicana. pp. 457-464.

El-Hani, C. (2001). Por que a entnobiologia e a etnoecologia são importantes? Uma resposta do ponto de vista da educação [Why ethnobiology and ethnoecology are important? An answer from educational point of view]. Proceedings of I Baian Meeting of Etnobiology and Etnoecology. 
Feira de Santana: State University of Feira de Santana. pp. 91-108.

Fagundes, T.B. (2016). Os conceitos de professor pesquisador e professor reflexivo: Perspectivas do trabalho docente [The concepts of a researcher teacher and reflective teacher: perspectives of teaching work]. Revista Brasileira de Educação, 21(65), 281-298.

International Society of Ethnobiology (ISE). (2018). Who we are. Available from: http://www.ethnobiology.net/about. [Last accessed on 2018 Mar 3].

Martins, H.T.S. (2004). Metodologia qualitativa de pesquisa [Qualitative research methodology]. Educação e Pesquisa, 30(2), 289-300.

Nascimento, A.RT., Santos, A.A., Martins, R., \& Dias, T.A.B. (2009). Comunidad de palmeras en el territorio indígena Krahò, Tocantins, Brasil: Biodiversidad y aspectos etnobotánicos [Community of Palmeras into indigenous territory Krahò, Tocantins, Brazil: Biodiversity and ethnobotanical aspects]. Interciencia, 34(3), 182-188.

Nóvoa, A. (1992). Os professores e sua formação [The teachers and their training]. Lisboa, Portugal: Dom Quixote.

Osborne, J., Erduran, S., Simon, S., \& Monk, M. (2001). Enhancing the quality of argument in school science. School Science Review, 82(301), 63-70.

Pérez-Ramírez, L., Moreno-Fuentes, A., \& Aguirre-Acosta, E. (2004). Conocimiento tradicional y científico de los Hongos en el estado de
Chihuahua, México [Traditional and scientific knowledge of fungi in the Chihuahua State, Mexico]. Etnobiología, 4, 89-100.

Posey, D.A. (1997). Etnobiologia: Teoria e prática [Ethnobiology: Theory and practice]. In: Ribeiro, D., (Ed.), Suma Etnológica Brasileira. [Brazilian Ethnological Summary]. $3^{\text {rd }}$ ed., Vol. 1. Petrópolis, Brazil: Vozes/FINEP. pp.1-15.

Righetti, S. (2004). Pesquisas ganham espaço nas universidades mas área ainda é pouco divulgada no país [Research gain space in universities but area is still little known in the country]. Ciencia e Cultura, 56(3), 8.

Sasseron, L.H., \& Carvalho, A.M.P. (2014). A construção de argumentos em aulas de ciências: O papel dos dados, evidências e variáveis no estabelecimento de justificativas [The construction of arguments in science classrooms: The role of data, evidence and variables in establishing justifications]. Ciência and Educação, 20(2), 393-410.

Schön, D.A. (1992). Formar professores como profissionais reflexivos [Training teachers as reflective practitioners]. In: Nóvoa, A., (Ed.), Os Professores e a sua Formação. [The teachers and their training]. Lisboa, Portugal: Dom Quixote. pp. 77-91.

Tardif, M. (2002). Saberes Docentes e Formação Professional [Teaching knowledge and vocational training]. Petrópolis, Brazil: Vozes.

Zion, M., \& Mendelovici, R. (2012). Moving from structured to open inquiry: Challenges and limits. Science Education International, 23(4), 383-399. 